\title{
Interações supervisor-professor: diálogos de proteção da face
}

\author{
Supervisor-Teacher Interactions: \\ Dialogues for Face Protection
}

\author{
Simone Correia Tostes* \\ Centro de Estudos de Pessoal e Forte Duque de Caxias (CEP/FDC) \\ Rio de Janeiro - Rio de Janeiro/Brasil
}

RESUMO: Partindo de uma perspectiva funcional do uso da língua, investigamos as estratégias linguísticas do supervisor escolar e sua aceitação pelos docentes. Tal estudo visa a oferecer insights sobre a modalização da linguagem em interações profissionais. Assim, utilizamos princípios da Teoria da Polidez (1978) aliados à Teoria dos Atos de Fala (1962) para chegar à relação inversamente proporcional entre o grau de polidez e o conteúdo positivo dos comentários: quanto mais polidos os comentários, menos positivo seu conteúdo, e vice-versa. Testes de atitude aplicados aos professores revelam alto grau de aceitação dos comentários tecidos pelo supervisor, o que pode indicar que alto grau de polidez e modalização da linguagem em situaçōes de supervisão escolar são altamente desejáveis para se alcançar atuações profissionais mais eficazes.

PALAVRAS-CHAVE: Estratégias Comunicativas; Polidez; Supervisor; Docente.

ABSTRACT: Departing from a functional perspective of language use, we have investigated linguistic strategies of a school supervisor and their acceptance by teachers. Such study tries to offer insights on the modalization of language in professional interactions. Thus, we have applied principles of Politeness (1978) allied to the Speech Acts Theory (1962) to come to the conclusion there is an inverse proportion between the level of politeness and the quality of comments made: the more politeness strategies used, the less positive the comments made and vice-versa. Attitude tests reveal high level of acceptance of comments by teachers, what might indicate that more politeness and modalization of language in situations of supervision are highly desirable for more effective professional actions.

KEYWORDS: Communicative Strategies; Politeness; Supervisor; Teacher.

*stostes@gmail.com 


\section{Introdução}

Oferecer apoio pedagógico a docentes é uma das tarefas mais fundamentais do trabalho de supervisão escolar. A intervenção pedagógica do supervisor pode, inicialmente, parecer sem sentido se considerarmos que o professor é formado e preparado para atuar na docência da sua disciplina. No entanto, supervisor e docente podem estabelecer uma parceria valiosa em prol da educação. Nem mesmo vários anos de experiência no magistério prescindem das trocas de experiências e sugestóes entre colegas que podem ser incorporadas em curto espaço de tempo à prática pedagógica.

Apesar dos avanços e mudanças ocorridos na profissão de supervisor escolar, a visão errônea da atividade ainda persiste, sendo o profissional comumente visto como inspecionador da escola, "detector de erros" ou "fiscal de procedimentos". O entendimento equivocado do papel da supervisão escolar nas instituições de ensino justifica-se por uma tradição que se fundou na origem da profissão e na filosofia escolar tradicional, segundo a qual a escola podia ser vislumbrada como um conjunto de partes atuando independentemente umas das outras.

Mais do que um observador destacado do processo educativo, o supervisor deve estar envolvido como partícipe do sistema, ainda que suas atividades não incluam o exercício docente ou a aplicação direta de métodos e técnicas em sala de aula. As intervençôes do supervisor escolar geralmente ocorrem em reuniōes pedagógicas.

A hipótese inicial de nossa pesquisa consiste em verificar a atitude de professores em relação a esses momentos. Partimos do princípio de que, quanto mais cuidada for a linguagem do supervisor escolar ao abordar questóes pedagógicas com os professores, mais positiva será a aceitação das intervenções pelos docentes e a consequente implementação de melhorias em sua prática pedagógica. Em resumo, propomos que técnicas adequadas de feedback sobre a atuação docente podem influenciar diretamente sua aceitação por parte do professor.

\section{Fundamentação teórica}

\section{Funcionalismo linguístico}

Para analisar a linguagem do supervisor escolar, partimos de uma perspectiva funcional do uso da língua, segundo a qual a linguagem consiste em um produto da interação entre indivíduos. Dentro desse esquema, é dotada 
de significados na medida em que se compreendem os meandros do contexto de uso da língua. Faz-se importante ressaltar que, embora tenha como objeto de estudo estruturas linguísticas, o paradigma funcionalista compreende também toda a engrenagem social em que a fala é produzida - seu propósito, seus participantes e o contexto discursivo em que se insere (NICHOLS, 1984, p. 97). O ponto de vista funcionalista pode ser resumido de acordo com uma perspectiva que vê a linguagem como fenômeno dinâmico, que serve a uma função específica.

O termo função, em Linguística, pode servir para designar as relações entre uma forma linguística e outra, entre uma forma linguística e seu significado ou entre o sistema de formas e seu contexto. No presente estudo, interessamo-nos pela combinação da segunda e da terceira perspectivas, uma vez que elas dão conta de explicar determinadas formas e seus significados em função de contextos comunicativos.

Parece óbvio tratar-se do aspecto funcional da linguagem no momento em que consideramos que todos os eventos de expressão oral ou escrita cumprem determinada função. Entretanto, o conceito distintivo de função diz respeito ao efeito que as expressões linguísticas exercem nos interactantes. Adota-se uma abordagem da língua segundo a qual não se vislumbra mais um conjunto abstrato de regras, princípios e parâmetros, justificáveis em si mesmos e independentes dos indivíduos enquanto seres sociais. No paradigma funcionalista, a linguagem é resultado da dinamicidade de relações possíveis mediante o uso (HALLIDAY, 1973).

Do ponto de vista do destinatário, "[i]sso significa que a interpretação será apenas em parte baseada na informação contida na expressão linguística em si; igualmente importante é a informação que o destinatário já possui” (MOURA-NEVES, 2001, p. 20-21).

Assim, para ser completa, uma descrição linguística deve dar conta da referência ao falante, ao ouvinte e a seus papéis sociais, pois, da mesma forma que um texto somente adquire significado na medida em que é decodificado e interpretado por seu leitor, também a língua somente adquire vida quando os participantes do discurso interpretam significados de acordo com seu conhecimento de mundo e suas experiências.

O estudo da conversação provê insights sobre a pragmática do discurso. Isso significa dizer que, além de estruturas morfofonêmicas e seus significados, temos como acessar informações significativas a respeito das intenções do falante ao se dirigir a seu interlocutor. Essas intençōes e a forma como elas 
foram veiculadas no discurso possibilitam um entendimento mais global da linguagem humana. Em suma, a pragmática estuda as relações entre a linguagem e o contexto na tentativa de descrever facetas do uso da língua em referência a aspectos linguísticos e não linguísticos.

Estudar as partes adjacentes ao discurso torna-se relevante na medida em que o significado de uma determinada sequência é mais do que o cálculo da soma de suas partes constituintes. Ou, dito de outra forma, o significado de uma frase somente pode ser compreendido em sua totalidade se se considerarem pistas contextuais que auxiliem sua decodificação.

\section{Teoria dos Atos de Fala}

Por esse motivo, convém abordarem-se princípios da Teoria dos Atos de Fala (AUSTIN, 1962), uma vez que dão conta de explicar melhor como utilizamos a linguagem para produzir efeitos em nossos interlocutores. A teoria de Austin lança o conceito de atos de fala perlocucionários, isto é, os eventos de fala que objetivam determinado efeito em seu interlocutor. Para bem ilustrar seu significado, é necessário estabelecer a distinção entre estes e os atos de fala ilocucionários. A diferença entre ilocução e perlocução reside no fato de a primeira representar uma ação posta em prática por meio de um proferimento convencionalmente reconhecido. Por outro lado, a perlocução refere-se às consequências ou efeitos que determinadas sequências linguísticas têm sobre o comportamento, a reação ou o sentimento das pessoas.

Assim, distingue-se o significado ilocucionário da frase "Que frio!" comentário sobre as condições de temperatura - de seu sentido perlocucionário - convencer o ouvinte a fechar uma janela. Se o efeito causado foi decorrente de palavras proferidas, mas não diretamente de seu significado imediato, temos aí configurado o ato perlocucionário. Em nosso estudo, é de se esperar que o supervisor escolar consiga ter seus comentários não apenas compreendidos, mas também aceitos por seus interlocutores, o que resultará no efeito perlocucionário de suas palavras.

Estudar os efeitos perlocucionários dos atos de fala configura-se como atividade de extrema importância para a ação educativa. O estudo do discurso dos agentes de gestão escolar torna-se relevante na medida em que se destaca como expressão das relações humanas e sociais que diferenciam a escola das demais empresas (LIBÂNEO; OLIVEIRA; TOSCHI, 2003). Assim, esperase que mais hábitos de trabalho em comum e espírito de equipe impliquem mais motivação e satisfação no exercício da profissão. 


\section{Teoria da Polidez}

Elaborada em 1978 por Brown e Levinson (BL), a Teoria da Polidez continua sendo amplamente evocada por dar conta de explicar as faces envolvidas na interação entre interlocutores. Segundo os autores, toda interação implica tensão constante entre as faces positiva e negativa do falante e do ouvinte. A face positiva é aquela que gostamos de compartilhar e expor em público; em geral, são nossas características positivas que deixamos transparecer nas interações sociais. Já a face negativa abrange todos os traços que procuramos ocultar, por considerarmos que nos desvalorizam frente aos nossos interlocutores.

Portanto, numa interação entre dois participantes, existem quatro faces que têm de estar em equilíbrio. Para dar conta desse equilíbrio, existem atitudes de polidez positiva e polidez negativa. A primeira dedica-se a preservar a face do falante, assim como de seu interlocutor, enquanto a segunda tem efeito negativo sobre essas faces.

Exemplos de polidez positiva são aqueles em que o falante procura "livrar a cara” do seu interlocutor em situações em que há riscos de ameaça à face. Vejamos uma situação em que isso pode acontecer: ao chegar atrasado para o trabalho, um funcionário dirige-se ao seu chefe para se justificar e coloca a justificativa do atraso no trânsito caótico da manhã. Ao fazer um comentário do tipo "É, o trânsito está cada vez pior", o chefe indiretamente aceita a justificativa apresentada e demonstra solidariedade com o problema do empregado.

Por outro lado, atitudes de polidez negativa, algumas vezes chamada de impolidez, evidenciam desconsideração da face do interlocutor, que pode ser afetada, uma vez que não se procura "acolchoar" os efeitos negativos de um comentário. Na mesma situação do atraso do empregado, um comentário do tipo "É só sair mais cedo" em resposta à justificativa enquadra-se nessa categoria. Dedicamo-nos, neste trabalho, a caracterizar diferentes enunciados de polidez positiva do supervisor escolar em reunião pedagógica com docentes.

A nova configuração do trabalho do supervisor escolar resultou da mudança da realidade imposta pela distância entre a vida real e a vida escolar, que promove a reflexão e a problematização. A escola passa de espaço de informação para espaço de reflexão. Assim,

O Supervisor abdica de exercer poder e controle sobre o trabalho do professor e assume uma posição de problematizador do desempenho docente, isto é, assume com o professor uma atitude de indagar, comparar, responder, opinar, duvidar, questionar, apreciar e desnudar situações de ensino, em geral, e, em especial, as da classe regida pelo professor (MEDINA, 1995, p. 46). 
Em vez da função fiscalizadora, o supervisor escolar tem agora sua atuação renovada e reconhecida como apoio e orientação do trabalho docente. Ele não só sugere perguntas, como indica possibilidades. Conforme sintetiza Rangel (1988, p. 13), a função do supervisor escolar abrange a "assistência ao professor, em forma de planejamento, acompanhamento, coordenação, controle, avaliação e atualização do desenvolvimento do processo ensinoaprendizagem". Em síntese, torna-se então "professor de seus professores" (ROLLA, 2006).

Por esse motivo, Medina (2007) ressalta que o supervisor precisa compreender que é na interação professor-aluno que se encontra o eixo principal da aprendizagem sistematizada na escola. Dentro desse esquema, os encontros pedagógicos entre supervisor e professor abandonam definitivamente seu caráter controlador e fiscalizador para se transformarem em focos de discussão e reflexão que ratificam ou redirecionam o fazer pedagógico em busca de ações repensadas de educação. Em síntese, o envolvimento do supervisor alavanca o trabalho do professor.

Para alcançar objetivos educacionais, supervisor e professor devem estabelecer o diálogo problematizador, em que se atendam a anseios coletivos, isto é, de forma que projetos que envolvam docentes e discentes sejam viabilizados, tomem direção e se concretizem. Para ser esse facilitador, o supervisor deve conquistar a confiança do grupo, pois a comunicação interna consolida os projetos educativos.

Assim, torna-se de relevância fundamental investigar o principal instrumento de trabalho com que pode contar o supervisor: a linguagem. É através da linguagem, em suas interaçóes com o professor, que o supervisor consegue implantar o sentimento de pertencimento no grupo, pelo uso de habilidades humanas, técnicas e administrativas. É principalmente nas relações humanas que se instala o ambiente de trabalho saudável entre os diversos setores da escola.

\section{Metodologia}

Para este estudo, seguimos o paradigma qualitativo de pesquisa científica. Em oposição à tradição de investigação quantitativa, a pesquisa qualitativa não pretende chegar a conclusões a partir da generalização estatística de fenômenos para compor leis universais. Em vez disso, concentra-se em estudar detalhes de uma situação específica. 
Dentro dessa perspectiva, pretende-se lançar mão da pesquisa de base etnográfica, cujo principal método de coleta e análise de dados é a observação participante. O termo etnografia foi cunhado no final do século XIX para referir-se a estudos que descreviam os modos de vida de povos até então desconhecidos. O termo é formado por dois radicais - ethnos, que significa "os outros", e graphos, que se refere a "escrita" ou "registro". O etnógrafo participa da vida diária da comunidade que está estudando, reunindo todas as informaçôes que possam estabelecer um perfil daquele determinado grupo.

A etnografia faz uso de métodos de observação tanto para a geração como para a análise dos dados. Com isso, ao mesmo tempo que participa da coleta de dados, o pesquisador atua também na análise e na sistematização desses dados, uma vez que integra o universo estudado, sendo capaz de entender suas variáveis. A pesquisa etnográfica normalmente combina observaçōes colhidas e guardadas em arquivos de áudio e vídeo, que permitem ao pesquisador acessar dados e falas que passam despercebidos no momento da interação.

Segundo Erickson (1988), a pesquisa de base etnográfica permite verificar aspectos do significado e do contexto em estudo não imediatamente disponíveis a qualquer observador. Isso é possível por se tratar de uma metodologia que acessa informaçóes registradas em dados da memória consciente dos participantes. A etnografia tem como objeto de estudo fundamental a fala que ocorre naturalmente, considerada como um modo de atividade social situado, bem como a cena imediata da vida social local, na qual a fala em si ocorreu.

Por se tratar de evento social situado, a pesquisa etnográfica tem seu foco no particular, isto é, as observaçôes e conclusōes verificadas em um evento discursivo somente se aplicam àquela situação específica. Portanto, é impossível exportá-las para outra experiência, uma vez que a percepção e o envolvimento dos participantes são aspectos inteiramente particulares. Assim,

A descrição etnográfica na pesquisa sociolinguística tem como interesse central os detalhes do desempenho situado, tal como ocorre naturalmente nas interações da vida diária. A etnografia documenta o que as pessoas realmente fazem ao falar e descreve, de modo muito específico, a fala e as situaçóes de uso (ERICKSON, 1988, p. 1084).

Outro pressuposto da pesquisa etnográfica é a triangulação dos dados, que possibilita a comparação entre os pontos de vista do pesquisador e dos participantes com o objetivo de se confirmarem ou refutarem conclusões do 
estudo. É essa fase da pesquisa que permitirá acesso a recursos que constroem e validam conclusões. Em última instância, a metodologia de microanálise etnográfica possibilita a compreensão abrangente e integrada dos eventos de fala específicos de determinado grupo social.

Em pesquisas que se voltam para o contexto da sala de aula, é comum o pesquisador etnógrafo se interessar pelos processos que se desvendam, e não pelos produtos finais (BORTONI-RICARDO, 2008). Portanto, busca "o desvelamento do que está dentro da 'caixa preta' na rotina dos ambientes escolares, identificando processos que, por serem rotineiros, tornam-se 'invisíveis' para os atores que deles participam” (p. 72).

Por configurar uma pesquisa que visa ao aperfeiçoamento de processos didático-pedagógicos, trata-se de uma pesquisa etnográfica colaborativa. Isso significa que a investigação pretende identificar estratégias interacionais que funcionam entre supervisor e professor. Portanto, além de prover insights sobre os processos que ocorrem na "caixa-preta" da escola, esse tipo de pesquisa visa a promover mudanças no ambiente pesquisado.

\section{Coleta de dados}

Os dados da pesquisa constituem eventos de fala colhidos em reuniōes pedagógicas realizadas com docentes após a observação de uma sequência didática presencial. Assim, antes do encontro pedagógico propriamente dito, o pesquisador frequentou uma sessão de aula da disciplina ministrada pelo docente. Com autorização dos entrevistados, procedeu-se à gravação das reuniōes em arquivos de áudio para posterior referência. Essa medida permitiu que o supervisor e o professor desenvolvessem uma interação mais próxima da conversa espontânea, já que se eliminou a necessidade de se registrarem informações durante a realização das entrevistas.

Por se tratar de registro em arquivos de áudio, não contemplamos nesta pesquisa os recursos paralinguísticos gestuais e corporais de que o supervisor faz uso em suas interaçôes. Da mesma forma, para reduzirmos o escopo da nossa pesquisa, não nos concentraremos em aspectos suprassegmentais como altura e ritmo, mas entendemos que eles podem exercer efeito significativo sobre o grau de aceitação das observações, podendo vir a ser objeto de estudo de pesquisas futuras. Os dados coletados foram selecionados de modo a se considerarem apenas as sequências em que o supervisor faz observaçóes e sugestões que visem ao aperfeiçoamento do trabalho docente. 


\section{Participantes e contexto}

\section{O supervisor escolar}

O profissional que desempenha a função de supervisor escolar da instituição de ensino superior onde se desenvolveu o estudo possui bacharelado e licenciatura em Letras (português-inglês), e mestrado e doutorado em Linguística. É militar de carreira com 19 anos de serviço. Já atuou como docente em estabelecimentos de ensino civis e militares nos níveis fundamental, médio e superior, bem como na instituição em que trabalha atualmente nos cursos de especialização e extensão como professor de Linguística e de Língua Inglesa, respectivamente.

\section{Os alunos}

Os alunos que compõem o corpo discente dos cursos de extensão em língua estrangeira são militares da ativa das Forças Armadas, os quais são designados para desempenhar principalmente as funções de adido ou de auxiliar de adido nas diversas aditâncias do Brasil no exterior.

Em geral, os futuros adidos são coronéis em fase final de carreira, bem conceituados o bastante para representarem seu país no exterior. Por ocuparem lugar de destaque entre seus companheiros de turma de formação, vários desses militares concorrem, mais tarde, a promoçóes ao generalato. Os auxiliares de adido são praças estabilizados, com mais de dez anos de serviço, nas graduações de primeiro-sargento ou subtenente, que se destacaram por seus relevantes serviços prestados ao longo da carreira. Tanto os adidos como seus auxiliares são selecionados de um universo de militares cadastrados para missões no exterior.

Para fazer parte desse universo, o militar deve necessariamente atender aos pré-requisitos linguísticos para a missão à qual é designado. Para isso, passa por um teste de verificação de proficiência linguística em um idioma de sua escolha. Realizado o diagnóstico, cada candidato recebe uma classificação composta de quatro algarismos, que é lançada em seus assentamentos, representando, respectivamente, as habilidades de ouvir, falar, ler e escrever no idioma estrangeiro considerado. Combinada com seu histórico militar, a proficiência linguística compóe o perfil que torna o profissional militar de carreira elegível para missōes no exterior. 


\section{Os professores}

Os sujeitos docentes considerados nesta pesquisa trabalham em uma instituição militar de ensino superior como professores de Espanhol como Língua Estrangeira. Nessa instituição, são ministrados cursos de especialização em diversas áreas das ciências humanas e de extensão em diferentes línguas estrangeiras.

O corpo docente da disciplina considerada é constituído por militares da ativa - de carreira ou temporários. A diferença entre esses dois tipos de docentes consiste na formação militar a que são submetidos, na progressão nos postos ao longo da carreira e na estabilidade na profissão. Os professores militares de carreira passam por processo seletivo em âmbito nacional para cursarem a escola de formação militar. Trazendo para o exército sua formação e experiência profissionais em diversas áreas do conhecimento, esses profissionais são submetidos a um período de formação militar de aproximadamente nove meses, ao término do qual o concluinte é declarado primeiro-tenente. De acordo com o interstício dos postos e com critérios de merecimento, esses oficiais são promovidos nos diversos postos da hierarquia militar até atingirem o posto máximo de tenente-coronel.

Os professores militares da ativa temporários passam por um processo seletivo local, que consiste em análise de currículo e entrevista para, em seguida, passarem por um estágio de formação militar com duração média de 45 dias, ao término dos quais são declarados aspirantes-a-oficial. Esses militares também ascendem hierarquicamente, podendo atingir até o posto de primeirotenente, uma vez que seu período máximo de permanência na instituição militar é de oito anos. Esses professores militares de carreira ou temporários usufruem de todos os deveres, direitos e prerrogativas da carreira militar.

Por serem ingressantes na instituição militar, foram solicitados a serem sujeitos da pesquisa a fim de se atingirem os propósitos deste estudo. Para preservar suas identidades, esses profissionais serão referidos apenas como P1, P2 e P3. Por possuírem experiência docente fora dos limites da instituição militar, torna-se relevante caracterizá-los por sua formação acadêmica, bem como por sua experiência na área de docência anterior a seu tempo de serviço militar.

\section{A instituição de ensino}

A instituição militar de ensino onde a pesquisa se realizou é um estabelecimento de ensino superior do exército que oferece cursos de pósgraduação lato sensu em diversas áreas das ciências humanas. O objetivo desses cursos é especializar mão de obra para atuação em funções de natureza 
complementar nas diversas escolas de formação do exército existentes no país. Funções de natureza complementar compreendem as atividades que não têm relação direta mas apoiam a atividade-fim da instituição militar - a defesa dos poderes constitucionais e a manutenção da soberania nacional.

Fundado há 46 anos, esse estabelecimento também realiza a seleção psicológica de militares para compor o efetivo da força de paz da ONU de estabilização em atuação no Haiti desde 2004. Outra missão altamente importante realizada na escola é o teste diagnóstico em vários idiomas nas quatro habilidades linguísticas para habilitação para missões no exterior.

Além dos cursos regulares de especialização oferecidos anualmente, compõem os quadros de trabalho docente estágios oferecidos em seis idiomas diferentes, a saber: alemão, espanhol, francês, inglês, italiano e russo. Nessas oportunidades, os militares permanecem durante oito semanas desligados totalmente de seus locais originais de trabalho para se dedicarem exclusivamente ao aperfeiçoamento no idioma da missão para a qual são designados.

As aulas de Espanhol que foram alvo da análise da supervisão escolar compõem essa formação especial e ocorreram no $2^{\circ}$ semestre de 2011. Nessa oportunidade, o estágio contou com 20 militares em preparação para missões no exterior. Após um teste diagnóstico, foram formadas duas turmas de aula - uma iniciante e outra intermediária - para dar andamento a essa preparação específica.

Entre os vinte estagiários que passaram por essa preparação, houve oficiais em vários postos (capitão, major, tenente-coronel e coronel) e praças na graduação de subtenente. Várias missões foram destinadas a esse pessoal: adidos, assessores, mestrandos, instrutores e auxiliares de adidos em diversos países da América Latina.

\section{Análise dos dados}

Após o registro da entrevista em arquivo de áudio e a posterior transcrição das sequências de supervisão, passamos a analisar as estratégias comunicativas empregadas pelo supervisor escolar quando de suas intervençóes nas reuniōes pedagógicas. Caracterizadas essas estratégias à luz das Teorias da Polidez e dos Atos de Fala, obtêm-se as primeiras informações sobre o discurso supervisor-pedagógico.

Um dos padrões que persistiram em todas as reuniōes registradas foi a necessidade de descaracterizar ou enfraquecer a situação vertical entre o agente da supervisão e os docentes. Por isso, apesar de configurar o discurso da autoridade, representando a figura do diretor ou comandante do estabelecimento 
de ensino, observa-se que o supervisor escolar procura, durante sua interação com os professores, amenizar esse aspecto da hierarquia, adotando estratégias comunicativas que mitigam a verticalização entre esses profissionais.

\section{Dados da observação didática de P1}

Ao comentar o desempenho do docente, o supervisor assume um tom de conversa e destaca a necessidade de se realizar uma aula mais dinâmica que exija mais participação do aluno. Assim, em vez de sentar-se à espera do conhecimento a ser ministrado pelo professor, destacou-se que é altamente desejável que o aluno desempenhe papel mais ativo, sendo também responsável pela aprendizagem. Fica evidente nessa oportunidade o receio e a insegurança do professor em relação a seus alunos de grau hierárquico superior. O docente então declara o propósito de não se indispor com seus alunos. De acordo com seu entendimento desse "novo" contexto da sala de aula em uma instituição militar, solicitar que alunos de grau hierárquico superior mudem sua disposição na sala de aula para a realização de tarefas em grupo configuraria uma transgressão disciplinar do professor.

Para justificar seu ponto de vista, o professor passa a expor algumas de suas limitações como pessoa. Em alguns momentos, o professor declara explicitamente que a dinâmica da sala de aula segue o perfil do militar de maior patente da turma. Segundo o docente, seria esse militar o responsável por ditar o "clima" na sala de aula. Se for uma pessoa mais sisuda, a turma assume uma postura mais séria; se, por outro lado, for mais descontraído, influencia na criação de um ambiente mais amistoso em sala de aula.

As intervenções da supervisão escolar tentaram descaracterizar e até mesmo desvalorizar essa hierarquia imposta pelas patentes militares para possibilitar uma mudança de ponto de vista do professor e a consequente reorganização dos trabalhos em sala de aula. Vejamos alguns exemplos em que isso acontece:

\section{"Acho que tinha que bagunçar aquela sala, sabia?" \\ "Pode reclamar, mas o professor é você." \\ "E eu acho que você tinha que tocar horror na sala."}

Em outros momentos, o supervisor destaca que a organização hierarquizada da sala de aula é danosa para a potencialização da aprendizagem: 
"Tá muito, assim, organizadinha, né, a aula, tá muito previsível, não tá?" "Aí fica muito... você já sabe como vai ser, né? O cara nunca é pego de surpresa ali."

"Modificar o sentido horário, né? Então, eu acho que você tem que mudar."

Ciente de questôes relacionadas à autoestima do professor, o supervisor faz uso de abordagem informal, de tom leve, com uso de gírias e expressões de efeito. $\mathrm{O}$ uso dessas expressões permite uma aproximação maior do professor; em algumas passagens, até mesmo o humor é utilizado como estratégia para possibilitar a aproximação e a descaracterização da formalidade da situação:

"Você é o cara para interromper, menino!"

"Mas você é a autoridade ali, cara."

"Joga lá pros teus monitores. Há, há, há, há."

Como maneira alternativa de lidar com as dúvidas dos alunos, o supervisor sugere uma técnica que tira do professor a responsabilidade de responder a todas as dúvidas dos alunos e divide com todos a construção do conhecimento. Com isso, o professor abdicaria da posição de detentor do saber, assim como retiraria o aluno da situação de "conforto" em que se encontra na sala de aula, atuando como mero receptor de conhecimento:

"Eles é que têm que pagar mico, não é você. Pagar mico que eu digo é 'se expor'. Eles não estão se expondo."

Para tentar atenuar o sentimento de baixa autoestima do professor, o supervisor faz comentários no sentido de valorizar a figura do professor em diversos momentos. Na maioria dessas passagens, verifica-se o uso do presente do indicativo para apresentar ao professor a realidade da sala de aula com que tem familiaridade na instituição militar. Em vez de crítica, essas observações têm como objetivo apresentar ao professor o panorama da sala de aula, bem como alternativas para a melhoria dos trabalhos:

"Vocêé o doutor ali na sala de aula. [...] Eles não sabem o que você sabe. Eu acho que você [es] tá subutilizando a sua capacidade."

"Você [es] tá ali porque você é um profissional. Ah, tudo bem: não é de artilharia, cavalaria, comunicações, infantaria. Mas você é de espanhol, a sua arma é a língua, né? [...]” 
"O professor que não corrige é mal visto. Esse aí é o seu instrumento de poder - e você tem que usar ele [...]."

"[...] aluno espera ser corrigido pelo professor."

"Você pode vir passando com um papelzinho [para anotar os erros]... Acho que você até se valoriza como professor."

"O livro é um meio auxiliar, mas você é o diretor dos trabalhos."

"Agora: segurança. Eu acho que você tem que demonstrar mais. Vocêé-o-cara. Lembra disso. Você não [es] tá lá emprestado; você passou por um processo seletivo."

Até quando usa o presente do indicativo em tom de imperativo, o supervisor visa a apresentar alternativas ao trabalho do docente:

"Joga o mico pra eles. Acho que vai te ajudar isso aí."

"Esquece esse negócio de disciplina."

Durante sua interação com o professor, o supervisor aproveita sua formação como professor de língua estrangeira e traz vários exemplos de atividades que poderiam dinamizar um pouco mais as aulas:

"Por exemplo, você põe em duplas [...]. Um lia a primeira parte e outro a segunda parte - agora troca: diz p[a]ra ele o que você leu."

"Mas e se você usar assim essas técnicas que tem de organização de grupos, né, por exemplo [...]."

Chama a atenção nessa última ocorrência o uso de palavras e expressões "retardadoras". Sem significado próprio nas frases em que são utilizadas, essas palavras servem unicamente para preparar o interlocutor para a ideia a ser apresentada. É como se o falante quisesse diluir seu discurso em meio a palavras vazias semanticamente para "ganhar tempo" para as "más notícias".

\section{Dados da observação didática de P2}

A atuação didática de $\mathrm{P} 2$ apresentou vários pontos positivos de destaque que ensejaram observaçóes elogiosas por parte do supervisor escolar. Ao lidar com esses aspectos positivos, observa-se a predominância de uso do tempo pretérito perfeito do indicativo para qualificar e classificar a sessão de aula observada. É possível destacar vários exemplos de uso desse tempo verbal: 
"A parte do início foi muito boa."

"É muito bom; essa parte do aquecimento foi muito legal."

"Também, é, p [a] ra ponto positivo, eu observei também sua atitude de firmeza para tirar dúvida."

"Demonstrou firmeza, né, na, na sua resposta. Isso é muito legal. Porque o aluno /.../. Pode até [es]ta[r] errado... Rs. Achei legal isso."

"Também foi boa sua atitude porque não teve aquele ô-ô..."

Ao fazer sugestões de melhoria de aspectos observados na sala de aula, o supervisor já adota um tom mais cauteloso e reticente para fazer suas observações. Isso fica evidenciado através do uso de expressões modalizadoras que atenuam o aspecto crítico do comentário. Vejamos alguns exemplos em que isso se verifica:

"Mas, não sei se você notou que eles ficam ali boiando - aqueles três."

Em outras passagens, o supervisor se utiliza de falas do próprio professor durante a reunião para justificar suas observaçôes, criando, com isso, uma atmosfera mais cooperativa, em que fica bem ilustrada a valorização do discurso do outro para construir seu próprio discurso. Isso configura uma técnica de alteridade, que consiste em tornar a contribuição do outro enriquecedora-de maneira bem simples, essa prática poderia ser traduzida com "eu só existo porque você existe":

"Eu achei - agora vou entrar naquilo que você falou antes - muitos erros nos exercícios - erros de pronúncia, né? É claro que você observou porque você até falou agora 'eles continuam errando, aí eu não corrijo mais'."

Evidencia-se no discurso do supervisor a necessidade de tornar impessoais as observações críticas ou sugestões, generalizando-as. Assim, em vez de se identificar como autor das observações, o supervisor passa a reportálas. Por meio desse recurso, consegue atenuar a ameaça que sugestôes diretas podem causar à face do professor:

“Tem umas - uns estudos que jál até em congressos já ouvi falar que o momento de corrigir é o momento em que ele não [es] tá usando, é, pra, pra se comunicar mesmo, então ele [es] tá lendo uma frase, ele [es] tá lendo um texto, né, e aí você vai corrigindo [...]." 
O tempo verbal futuro do pretérito é bastante utilizado para apresentar sugestões para a melhoria da atividade docente. Consiste em um recurso atenuador da força perlocucionária do ato de fala: ${ }^{1}$

"Uma outra solução seria você ir anotando essas palavras mais difíceis, né $[\ldots]$ ?.”

"Seria uma maneira de você potencializar os espaços de fala."

Outro recurso que serviu provavelmente para atenuar o tom imperativo das sugestões apresentadas foi o uso da locução adverbial "de repente". Essa expressão também imprime um caráter de casualidade às observações que estão sendo realizadas. É utilizada em vários momentos e em diversas posições na frase:

"Aí não sei, de repente sortear umas palavras ali e ir anotando no cantinho do livro, $\mathrm{p}$ [a] ra no final você fazer uma retificação da aprendizagem em grupo [...]."

"De repente, em vez de usar uma pessoa falando sozinha durante dois, três minutos, por que você não multiplica esse tempo? [...]"

"Então, de repente, aquela sua maneira de passar por cima [dos erros de pronúncia] não é o caso.”

Algumas vezes, o professor procura explicar por que tomou determinadas decisões durante a aula. Para demonstrar seu entendimento e sua concordância com a prática adotada, o supervisor dá um feedback positivo sobre a prática em questão. Isso é feito por meio de expressões como "entendi", "[es] tá certo", "isso â’, que demonstram aprovação da prática pedagógica adotada:

"Ah, entendi. [Es]Tá certo."

"É uma, é uma... atitude que você tomou que tem uma justificativa, porque ele tem que acompanhar os degraus, né, não adianta você querer chegar no $3^{\circ}$ e não passou pelo $1^{\circ}$, né? Certo - isso aí."

\section{Dados da observação didática de P3}

As observações sobre a aula de P3 foram bastante positivas, sendo destacados vários aspectos, como postura, voz, atitude, entusiasmo e didática.

\footnotetext{
${ }^{1}$ Castilho (2010, p. 434) faz referência a esse uso do futuro do pretérito como "metafórico", pois "manifesta opinião de modo reservado, ou nos usos de atenuações ou polidez".
} 
Nessas situaçóes de elogio do desempenho, verifica-se um discurso bastante descontraído do supervisor, que vai direto ao ponto para louvar as iniciativas positivas do docente. Novamente, verifica-se o uso do pretérito perfeito do indicativo ao expor observaçóes positivas sobre a aula. Ao empregar o presente simples do modo indicativo nesse tipo de intervenção elogiosa, evidencia-se a intenção de classificar ou até mesmo generalizar a atuação docente:

"Olha, a sua aula [...] teve muitos aspectos positivos a destacar. Eu coloquei alguns aqui, né:

A sua simpatia, né, na maneira de lidar com os alunos - realmente a gente vê que tem uma facilidade para você lidar, que aí envolve / a sua inteligência interpessoal fica evidenciada.

Energia para dar aula, né, não é aquela pessoa que você vê que a pessoa [es] tá se arrastando, né, para dar aula. Eu achei muito positiva a sua energia - e você transmite isso e você acaba contagiando os alunos também; muito legal.”

Os comentários feitos com o intuito de contribuir para a melhoria reuniram recursos comunicativos que já haviam sido observados anteriormente, como o uso do futuro do pretérito, que confere um ar de sugestão atenuada às observações, como em:

"Eu recomendaria no início você fazer um warm-up [aquecimento], né, [...], alguma coisa pra não entrar no assunto direto [...]."

"Eu não sei como você faria [sendo canhota para não dar as costas para os alunos]."

Também foi possível verificar o uso de expressões modalizadoras para mitigar o aspecto crítico das observaçoes feitas. Antes de realizar a crítica, o supervisor tenta atenuar os efeitos negativos que ela porventura possa causar. Observe-se a distância entre o tema da observação - sobre anotação no quadro - e a crítica propriamente dita.

"A parte da anotação no quadro, tem duas coisas que eu acho que você pode melhorar, você - não sei se você vai lembrar -, mas você faz, a tendência é você/ você é canhota, né, igual a mim. A tendência é a gente escrever e dar as costas, né, para o nosso público, né." 
Observe-se que, em sua fala, o supervisor se inclui como um dos professores que cometem esse tipo de equívoco, possibilitando um sentimento de identificação pelo professor.

Da análise dos dados, podem-se sintetizar os recursos linguísticos adotados pelo supervisor escolar de acordo com os padrões descritos no QUADRO 1, a seguir:

\section{QUADRO 1}

Síntese das estratégias do supervisor

\begin{tabular}{|c|c|c|}
\hline \multicolumn{3}{|c|}{ Características do discurso } \\
\hline & + real & - real \\
\hline $\begin{array}{l}\text { Elogios e } \\
\text { encorajamento }\end{array}$ & $\begin{array}{l}\text { - Presente simples } \\
\text { - Pretérito perfeito }\end{array}$ & \\
\hline Sugestōes e críticas & & $\begin{array}{l}\text { - Futuro do pretérito } \\
\text { - Expressōes de casualidade e } \\
\text { distanciamento, como “de repente", } \\
\text { "não sei se você notou" }\end{array}$ \\
\hline
\end{tabular}

Por não representarem atos de potencial ameaça à face do falante, bem como de seu interlocutor, verifica-se a característica de diretividade no discurso do supervisor ao elogiar e encorajar os docentes - com isso, predomina o uso de tempos verbais como o presente simples e o pretérito perfeito do indicativo, que denotam a ocorrência de açóes que efetivamente se realizaram. Por outro lado, o supervisor tenta tornar o discurso "menos real", menos categórico ou até mesmo mais distante de si ao fazer críticas e sugestôes ao trabalho dos professores, o que é conseguido através do uso de tempos verbais mais distantes na mente do falante/ouvinte (sendo este o caso de frases com verbos no futuro do pretérito, que encerram açôes que, em princípio, só ocorreriam caso fosse preenchida determinada condição). $\mathrm{O}$ uso de locuções adverbiais como "de repente" também imprime esse tom casual descomprometido com a efetiva ocorrência dos fatos. Em resumo, é de se supor que haja uma relação direta entre a proximidade do discurso do supervisor e a avaliação realizada da atuação docente, que pode ser sintetizada nas seguintes expressóes:

\section{Triangulação dos dados}

Outros dados considerados na análise são as respostas aos questionários de atitude linguística dos docentes, que foram convidados a refletir sobre a 
qualidade da interação, a adequação e o tom da linguagem utilizada quando das intervençôes realizadas pelo supervisor escolar nas reuniōes pedagógicas. Esses dados permitirão a triangulação dos dados através da comparação entre a análise da conversação pela pesquisadora e as impressões dos docentes sobre a qualidade da interação estabelecida.

A fase de triangulação dos dados ocorreu por meio da aplicação de um questionário em que o docente registrou suas percepções sobre o desenvolvimento da reunião pedagógica. O questionário foi, então, aplicado aos três professores considerados na pesquisa. Composto de 10 questôes, sendo sete objetivas e três dissertativas, o questionário coletou informaçôes a respeito do aproveitamento dos assuntos tratados nas ocasiōes para a melhoria do desempenho docente. As perguntas focaram basicamente o tom das interaçōes supervisor-professor durante as reuniōes pedagógicas.

Sobre a presença do supervisor escolar na sala de aula, apenas um dos professores a considerou constrangedora. Os três professores classificaram como positivo o tom da conversa com o supervisor escolar, proporcionando proximidade entre os participantes. Os docentes entrevistados perceberam como sugestôes (e não como ordens) e consideraram bastante úteis as observaçôes feitas sobre sua atuação didática. Após a realização dessa atividade pedagógica de supervisão escolar, foi consenso entre os professores sentir-se à vontade para consultar a supervisão escolar em caso de necessidade.

A respeito da condução da conversa, um professor declarou explicitamente ser o tom o aspecto mais positivo da reunião. Os demais professores apontaram que as sugestôes propriamente ditas foram o ponto mais positivo na condução da conversa. Um deles destacou a importância da apresentação de críticas construtivas como fator de contribuição para seu crescimento profissional.

\section{Conclusão}

Conhecer e realizar uma autoanálise do seu trabalho deve ser uma preocupação de qualquer profissional. Neste estudo, concentramo-nos em investigar os padrões linguísticos evidenciados por ocasião de interações supervisor-professor em reuniōes pedagógicas. Isso proporcionou insights valiosos sobre usos linguísticos que podem ser eficazes na atividade de apoio da supervisão escolar.

Foram observadas três sessóes de aula de três professores de Espanhol de uma mesma instituição de ensino. Por serem ingressantes no sistema de ensino especificamente militar, pensamos que observar essas aulas seria de grande utilidade 
para nossa investigação, pois era de se esperar que houvesse vários aspectos que merecessem ser alinhados à filosofia do estabelecimento de ensino militar.

Por serem militares temporários do exército brasileiro, era de se supor que esses professores, recém-egressos na instituição, apesar de já terem experiência docente no meio civil, evidenciassem dificuldades ao lidar com a questão da hierarquia militar, uma vez que grande parte de seus alunos possuía grau hierárquico superior nessa nova realidade escolar.

Ao observarem-se as aulas, constatou-se a dificuldade de apenas um dos professores ao lidar com oficiais de maior patente na hierarquia militar. Os demais professores não apresentaram limitações quanto à hierarquia imposta pelos vários postos presentes durante as sessões de aula. Esse fato requereu diferentes abordagens por parte do supervisor. Para cada uma das situações verificadas, o profissional da supervisão escolar adaptou seu discurso de forma a conseguir atingir seus objetivos nas reuniōes pedagógicas.

De um lado, foi necessário imprimir tom mais assertivo nas observaçôes feitas sobre a sessão de aula daquele professor com dificuldades. Para atenuar esse tom, foi possível destacar o toque de informalidade, caracterizado pelo uso de gírias e expressóes coloquiais, e até mesmo de traços de humor para imprimir tom amistoso à conversa. De outro lado, ao verificarem-se a fluidez e o ritmo que os demais professores adotaram em sala de aula, ficou observada a mudança de tom por parte do supervisor escolar, que passou a usar expressóes modalizadoras, frases com efeito de retardo e até tempos verbais menos reais - que descrevem açóes que não ocorreram - para tratar dos aspectos a serem discutidos.

Verificam-se nessas estratégias tentativas de proteger a própria face, bem como a de seu interlocutor, mantendo a dinâmica do discurso equilibrada. Por um lado, o supervisor escolar tenta ser aceito pelo corpo docente durante a realização de seu trabalho, e para isso adota tom amistoso de cooperação com o trabalho didático docente. Por outro lado, apresenta suas observações em forma de sugestōes, isto é, confere ao professor a autoridade para aceitá-las ou não.

A aplicação dos questionários de avaliação do trabalho realizado durante as reuniōes pedagógicas demonstrou boa aceitação das intervenções do supervisor pelos professores. Todos os professores declararam perceber como sugestões as observações apresentadas durante as reuniōes. Por fim, todos consideraram o trabalho da supervisão útil para a melhoria dos processos de ensino.

O supervisor escolar utiliza com proficiência sua competência de falante nativo e consegue equilibrar as quatro faces envolvidas nas reuniōes pedagógicas ao dosar proximidade e diretividade com a expectativa de aceitação pelo 
interlocutor. Dessa forma, de um lado, utilizou tempos verbais de decodificação mais imediata na mente humana para elogiar e destacar procedimentos positivamente; de outro lado, resguardou-se e aos seus interlocutores ao tecer comentários críticos ou apresentar sugestóes de melhoria do trabalho em sentenças com tempos verbais de processamento mais distante na mente humana, assim como com palavras e expressões retardadoras.

Vale destacar que o trabalho de pesquisa realizado permitiu compreender melhor a dinâmica que envolve os elementos de gestão e docência da escola. É por meio da realização desse tipo de pesquisa que acreditamos ser possível caracterizar o discurso da eficácia nas atividades de supervisão escolar. De maneira mais geral, conseguem-se insights sobre as características do líder ao incentivar seus colaboradores para realizarem um trabalho de excelência por meio do uso adequado de seu principal instrumento de trabalho: a linguagem.

\section{Referências}

AUSTIN, J. L. How to do things with words. Oxford: Clarendon Press, 1962.

BORTONI-RICARDO, S. M. O professor pesquisador. São Paulo: Parábola Editorial, 2008.

BROWN, P.; LEVINSON, S. Politeness: some universals in language usage. Cambridge: Cambridge University Press, 1978.

CASTILHO, A. T. Nova gramática do português brasileiro. São Paulo: Contexto, 2010.

ERICKSON, F. Ethnographic Description. In: AMMON, U.; DITTMAR, N.; MATTHEIER, K. J.; TRUDGILL, P. (Ed.). Sociolinguistics. Berlin; New York: Walter de Gruyter, 1988. v. 2. p. 1081-1095.

HALLIDAY, M. A. K. Explorations on the functions of language. London: Edward Arnold, 1973.

LIBÂNEO, J. C.; OLIVEIRA, J. F.; TOSCHI, M. S. Educação escolar: políticas, estrutura e organização. São Paulo: Cortez, 2003.

MEDINA, A. S. Supervisão escolar: da ação exercida à ação repensada. Porto Alegre: EDIPUCRS, 1995.

MEDINA, A. S. Supervisor escolar: parceiro político-pedagógico. In: SILVA JR., C. A.; RANGEL, M. (Org.). Nove olhares sobre supervisão. Campinas: Papirus, 2007. p. 9-36.

MOURA-NEVES, M. H. A gramática funcional. São Paulo: Martins Fontes, 2001. 
NICHOLS, J. Functional theories of grammar. Annual Review of Anthropology, n. 13, p. 97-117, 1984.

RANGEL, M. Supervisão pedagógica: um modelo. 5. ed. Petrópolis: Vozes, 1988. ROLLA, L. C. S. Liderança educacional: um desafio para o supervisor escolar. 2006. 129 f. Dissertação (Mestrado em Educação) - Faculdade de Educação, Pontifícia Universidade Católica do Rio Grande do Sul, Porto Alegre, 2006.

Recebido em 03/07/2013. Aprovado em 15/10/2013. 